\title{
Composição Química e Fracionamento do Nitrogênio e dos Carboidratos do Capim- Tanzânia Irrigado sob Três Níveis de Resíduo Pós-pastejo ${ }^{1}$
}

\author{
Marco Antonio Alvares Balsalobre ${ }^{2}$, Moacyr Corsi ${ }^{3}$, Patricia Menezes Santos ${ }^{4}$, Ivan Vieira ${ }^{5}$, \\ Ramiro Ruiz Cárdenas 6
}

\begin{abstract}
RESUMO - Amostras simulando o pastejo de capim-Tanzânia (Panicum maximum Jacq.) irrigado sob três resíduos pós-pastejo (baixo, médio e alto) foram coletadas ao longo de um ano e analisadas para a determinação da composição protéica e dos carboidratos, e das frações protéicas e de carboidratos (CNCPS). O teor de NDT foi calculado. Não foi encontrada diferença entre os tratamentos ao longo do ano. Os maiores teores de fibra em detergente neutro - FDN (68,3 a 64,5\%) e fibra em detergente ácido - FDA (34,89 a 33,18\%) ocorreram no período de primavera/verão. A lignina apresentou maiores proporções no inverno (4,68 a 4,10\%), o que provocou variação na fração C dos carboidratos (14,14 a 23,21\% dos carboidratos totais). O NDT variou entre 55,26 e 59,31\%. O teor de PB apresentou tendência de aumento ao longo do ano, variando de 11,29 a 14,61\%. Os teores de nitrogênio não-protéico $(\mathrm{NnP})$ variaram entre 18,23 e 28,77\% PB, sendo menor para os pastejos de primavera/verão. O Nsol variou de 24,97 a 35,97 \% PB. A fração de nitrogênio aderido à FDN (nFDN) foi, em média, de 49,11\%PB. Para o nitrogênio aderido à FDA (nFDA), a variação foi de 6,48 e 11,94 \%PB. A menor qualidade da planta foi entre julho a setembro, podendo estar relacionada à menor renovação de tecidos durante o período de inverno e ao acúmulo de perfilhos florescidos. A maior proporção do N encontra-se na parede celular (fração B3) e foi, em média, de 40\%PB, indicando que essa fração deve ter prioridade de estudo no tocante à cinética de degradação ruminal.
\end{abstract}

Palavras-chave: carboidrato, Cornell, NDT, Panicum maximum, proteína

\section{Nutriotinal Quality of Irrigated Tanzaniagrass under Three Post Grazed Stubbles Intensities}

\begin{abstract}
The objective of this work was to determine the chemical composition of irrigated Tanzaniagrass (Panicum maximum Jacq.). and to validate the Cornell system. Simulated-grazed samples were collected on three periods of the year (spring, summer and fall, totaling 10 grazing cycles) on irrigated paddocks, rotationally grazed to three post grazed stubbles (low, medium and high). Although there were no statistical differences imposed by the treatments during the year, the neutral detergent fiber (NDF) and acid detergent fiber (ADF) showed higher values in the spring/summer, and lignin in the winter grazing cycles. Along the year the carbohydrate $\mathrm{C}$ fraction, TDN and CP varied from 14.14 to $23.21 \%, 55.26$ to $59.31 \%$ and 11.29 to $14.61 \%$, respectively. The Nsol, non protein nitrogen (NNP) and nitrogen on ADF (nADF) (as CP\%) varied from 18.23 to $28.77 \%, 24.97$ to $35.97 \%$ and $6.48 \%$ to $11.94 \%$, respectively. The average nitrogen on NDF (nFDN) (as CP\%) was $49.1 \%$. From July to September forage quality was the lowest, probably due to the slowest tissue replenishment and flowering tillers accumulation. The $\mathrm{N}$ largest proportion (average of $40 \%$ of the CP fraction) was recovered in the cell wall, specifically in the B3 fraction, which should be the most important fraction on ruminal fermentation kinetics studies.
\end{abstract}

Key Words: carbohydrate, Cornell, Panicum maximum, protein, TND

\section{Introdução}

A estacionalidade da produção forrageira no Brasil Central é um fenômeno conhecido e estudado, decorrente de uma menor produção de forragem entre os meses de maio a outubro. Isso ocorre devido à redução da precipitação pluvial, da temperatura e da luminosidade nessa época. A estacionalidade de produção, no entanto, também pode ser decorrente de características fisiológicas das plantas. A maioria das plantas tropicais apresenta uma fase reprodutiva, que se inicia em resposta à redução no fotoperíodo. Ocorrendo o florescimento, a planta reduz sua produção e perde qualidade, pois há um aumento da relação haste/folha (Santos et al., 1999).

No caso do capim Tanzânia (Panicum maximum Jacq.), o florescimento se dá após o mês de abril, quando o fotoperíodo passa a ser menor que 12

\footnotetext{
1 Parte da tese de doutorado do primeiro autor. Trabalho financiado pela FAPESP.

2 Aluno de doutorado em Ciência Animal e Pastagem, ESALQ/USP, Piracicaba. E.mail: maabalsa@carpa.ciagri.usp.br

3 Prof. Titular do Depto de Produção Animal, ESALQ/USP, Piracicaba. E.mail: moa@carpa.ciagri.usp.br

4 Pesquisadora da Embrapa Pecuária Sudeste, São Carlos. E.mail: patricia@cppse.embrapa.br

5 Aluno de doutorado em Energia Nuclear na Agricultura, CENA, Piracicaba. E.mail: ivantg@cena.esalq.usp.br

${ }^{6}$ Aluno de mestrado em Estatística e Exp. Agr., ESALQ/USP, Piracicaba. E.mail: rrcarden@carpa.ciagri.usp.br
} 
horas. Os mecanismos que determinam o florescimento em plantas forrageiras tropicais, entretanto, ainda não são bem conhecidos, podendo esse estar relacionado a outros fatores climáticos, como, por exemplo, o hidroperíodo. Plantas irrigadas, portanto, podem apresentar comportamento diferenciado de florescimento quando comparadas às plantas de sequeiro, o que provocaria uma outra tendência na variação da qualidade dessas plantas.

O estresse hídrico, por outro lado, promove melhoria na qualidade da forragem, pois determina aumento da digestibilidade da MS e redução da relação haste/folha (Halim et al., 1989). Períodos prolongados de estresse hídrico, no entanto, podem promover o aumento da espessura da parede de células do esclerênquima (Paciullo et al., 1999), dificultando o ataque dos microorganismos no rúmen (Wilson \& Mertens, 1995) e, conseqüentemente, reduzindo a digestibilidade do material.

A busca por maiores produtividades na pecuária esbarra no melhor aproveitamento das altas produções que podem ser alcançadas com as gramíneas tropicais. Hillenshein (1987), trabalhando com capim-elefante (Pennisetum purpureum schum.), observou que o aumento da intensidade de desfolha determinava uma menor perda de forragem e, consequentemente, uma maior eficiência de pastejo. No entanto, níveis de resíduos pós-pastejo muito baixos podem proporcionar menor desempenho animal, pois, nesse caso, os animais apresentam maior dificuldade de apreensão da planta, o que reduz o consumo de forragem (Burlison et al., 1991).

As plantas manejadas com menores resíduos, podem apresentar melhor qualidade nutricional, devido à maior renovação de tecidos (Santos et al., 2001) e à maior proporção de folhas (Aguiar et al., 2001). No entanto, apesar das plantas manejadas a maiores alturas poderem apresentar pior qualidade, esse efeito pode ser minimizado pela capacidade dos animais em selecionar as melhores partes da forragem.

Pastagens de capim-Tanzânia manejadas em alturas de 25, 44, 52 e $75 \mathrm{~cm}$, apresentaram, nas menores alturas de pastejo, maior teor de proteína, menores teores de FDN e FDA e maior digestibilidade da matéria seca. Entretanto, ao longo das coletas, entre janeiro e maio, houve redução da digestibilidade da forragem e essa foi melhor explicada pela ordem da coleta do que pela altura da planta (Rego et al., 2001).

O surgimento do programa de Cornell (Sniffen et al., 1992; Fox et al., 1992, Russel et al., 1992) demonstrou a necessidade de melhor caracterização dos alimentos. Esse programa nutricional parte de um modelo dinâmico que leva em consideração a interação dos diferentes componentes dos alimentos, e tem por objetivo adequar a digestão ruminal dos carboidratos e das proteínas, visando maximizar a produção microbiana, a redução das perdas do nitrogênio pelo animal e estimar o escape ruminal de nutrientes.

Sniffen et al. (1992), dividem a proteína das plantas em cinco frações. A parte solúvel da proteína é dividida em fração A e B1. A fração A, é o nitrogênio não protéico $(\mathrm{NnP})$, essa é de alta digestibilidade no rúmen. O restante da fração solúvel (B1) é uma parte da proteína verdadeira, que também tem rápida degradação ruminal. A fração $\mathrm{C}$, corresponde à proteína indisponível e é a parte da proteína contida na FDA (nFDA). Está associada com a lignina, formando complexos de tanino e de produtos da reação de Maillard que são altamente resistentes à degradação microbiana e enzimática.

Existe uma fração do nitrogênio contido na FDN, designada de nFDN. A subtração do nFDA do nFDN é uma outra forma da proteína na planta. Essa estaria disponível, porém com uma taxa de degradação muito lenta, é a fração B3 (Sniffen et al., 1992). A última fração, a B2, apresenta taxa de degradação média, é a fração da proteína que não é solúvel, não faz parte da parede celular e também não é $\mathrm{NnP}$.

Os teores de nitrogênio ligados aos compostos da parede celular tendem a aumentar com a idade fisiológica da planta, principalmente, aquela fração ligada a FDA. Lima et al. (1999) encontraram redução linear na fração da proteína de lenta degradação (fração B3) com a maturidade de plantas de Tifton85 (Cynodon dactylon), Bahia (Paspalum notatum) e Floralta (Hemarthria altissima). Essa redução foi em detrimento do aumento da fração $\mathrm{C}$.

Malafaia et al. (1997) encontraram para quatro plantas tropicais (Tifton-85, capim-elefante, Brachiaria brizantha e Brachiaria decumbens) valores para a fração $C$ variando entre 11,66 e 27,73 \%PB. A fração A variou de 11,58 a 32,28 \%PB, enquanto as frações B1, B2 e B3 tiveram variações entre 0,58 e 4,54; 32,97 e 43,62; 17,55 e 34,17 \%PB, respectivamente. Nesse trabalho a Brachiaria brizantha apresentou a pior qualidade da proteína (a soma das frações B3 e C, foi de 51,90 \% PB) e a Brachiaria decumbens a menor proporção da proteína na forma das frações C e B3 (a soma de 29,21 $\%$ PB). A Brachiaria decumbens também apresen- 
tou o maior valor para a fração A, $32,28 \%$ e a Brachiaria brizantha o menor, 11,58 \% PB.

Os carboidratos também são fracionados. A porção C é a parte indisponível, a fração A são os carboidratos solúveis, a fração B1 corresponde ao amido e a fração B2 à parte potencialmente degradável da parede celular.

As gramíneas tropicais apresentam teores de carboidratos solúveis e amido (frações A e B1) raramente superiores a $20 \%$ dos carboidratos totais (CT) (Vieira et al., 2000). A fração indisponível (C) depende do teor de lignina, portanto, plantas de idade fisiológica mais avançada apresentam maiores teores dessa fração. $\mathrm{O}$ aumento da fração $\mathrm{C}$ promove redução da fração potencialmente degradável (B2) (Caballero et al., 2001).

O objetivo do presente experimento foi detalhar a qualidade nutricional das plantas de capim-Tanzânia manejadas sob três resíduos pós-pastejo (baixo, médio e alto) em uma área irrigada ao longo de um ano.

\section{Material e Métodos}

O experimento foi conduzido na Fazenda Areão da Escola Superior de Agricultura "Luiz de Queiroz" da Universidade de São Paulo, em Piracicaba, São Paulo ( $22^{0} 42^{\prime} 30$ " lat. S; 47 38'00' long. W; 546 m altitude). Foi utilizado o capim Tanzânia (Panicum maximum Jacq.) estabelecido em área irrigada por meio de pivô central. A pastagem foi manejada pelo método de pastejo rotacionado com 33 dias de descanso e três dias de ocupação, utilizando-se machos castrados da raça nelore com peso médio inicial de $270 \mathrm{~kg}$. Os tratamentos foram constituídos de três níveis de resí- duo pós-pastejo: baixo, médio e alto. Os valores de resíduo pós-pastejo, ao longo do ano, constam na Tabela 1. O delineamento experimental foi de blocos completos ao acaso com quatro repetições. Cada parcela foi dividida em três piquetes de $1.330 \mathrm{~m}^{2} \mathrm{com}$ o objetivo de facilitar o manejo, possibilitando o ciclo de pastejo proposto. As amostragens foram sempre realizadas no mesmo piquete de cada parcela.

O solo foi corrigido para garantir os seguintes níveis de fertilidade: saturação por bases de $80 \%$; fósforo de $30 \mathrm{mg} / \mathrm{dm}^{3}$; e potássio de $5 \%$ da CTC. Imediatamente após cada pastejo, os piquetes foram adubados com $80 \mathrm{~kg} / \mathrm{ha}$ de $\mathrm{N}$ e $80 \mathrm{~kg} / \mathrm{ha}$ de $\mathrm{K}_{2} \mathrm{O}$ em todos os ciclos de pastejo ao longo de 1 ano.

A pastagem foi formada em abril de 1999. O primeiro pastejo foi realizado em agosto de 1999; mais dois pastejos se sucederam, os quais foram

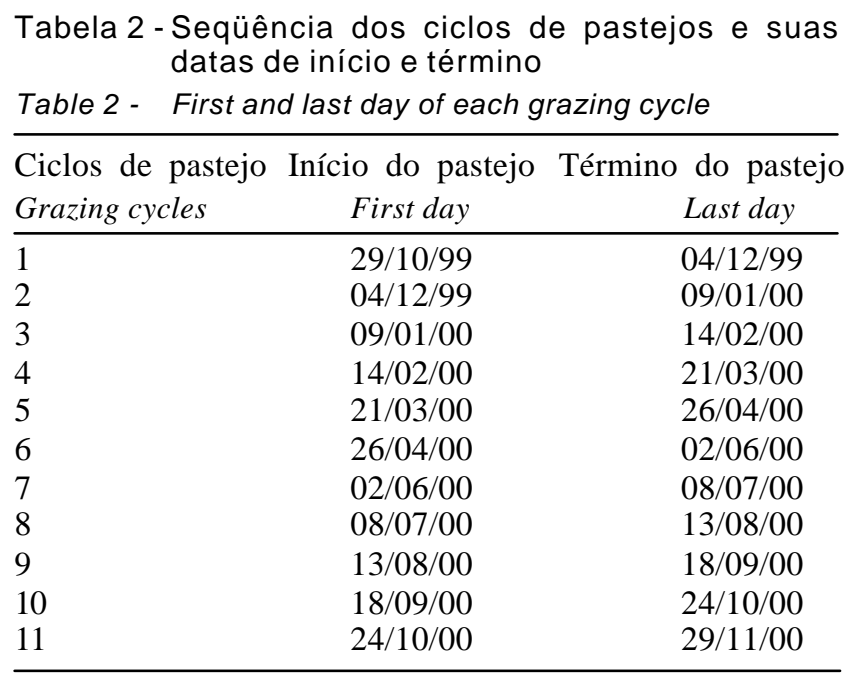

Tabela 1 - Resíduo pós-pastejo, expresso em kg de MS verde de forragem (kg MSV/ha), ao longo de quatro épocas do ano para os três tratamento (resíduo baixo, médio e alto)

Table 1 - Post grazing dry matter residue (kg GDM/ha) during four periods of the year for low, medium and high post grazing residue treatments

\begin{tabular}{lllll}
\hline $\begin{array}{l}\text { Tratamento } \\
\text { Treatment }\end{array}$ & $\begin{array}{c}\text { Época } 1 \\
\text { Period } 1\end{array}$ & $\begin{array}{c}\text { Época 2 } \\
\text { Period 2 }\end{array}$ & $\begin{array}{c}\text { Época } 3 \\
\text { Period 3 }\end{array}$ & $\begin{array}{c}\text { Época } 4 \\
\text { Period 4 }\end{array}$ \\
\hline & & kg MSV/ha $(k g$ GDM/ha) & \\
Baixo (Low) & $1277^{\mathrm{Aab}}$ & $1763^{\mathrm{Aab}}$ & $816^{\mathrm{Ab}}$ & $1210^{\mathrm{Aab}}$ \\
Médio (Medium) & $2459^{\mathrm{Ba}}$ & $3346^{\mathrm{Bb}}$ & $2548^{\mathrm{Bab}}$ & $3306^{\mathrm{Bb}}$ \\
Alto (High) & $3106^{\mathrm{Ca}}$ & $5335^{\mathrm{Cb}}$ & $3113^{\mathrm{Ca}}$ & $5471^{\mathrm{Cb}}$ \\
\hline
\end{tabular}

1 Época 1 - 29/10/1999 a 14/02/2000 (Period 1 - 10/29/1999 to 02/14/2000).

Época 2 - 15/02/2000 a 02/06/2000 (Period 2 - 02/15/2000 to 06/02/2000).

Época 3 - 03/06/2000 a 13/08/2000 (Period $3-06 / 03 / 2000$ to 08/13/2000).

Época 4 -18/09/2000 a 29/11/2000 (Period 4 - 09/18/2000 to 11/29/2000).

Médias seguidas da mesma letra, maiúscula na coluna ou minúscula na linha, não diferem significativamente pelo teste Tukey $(P>0,05)$.

Means followed by the same small/capital letter in the column/row do not differ $(P>$.05). 
chamados de pastejo de uniformazação dos tratamentos. A data de realização de cada pastejo consta na Tabela 2.

As amostras eram coletadas antes da entrada dos animais no piquete. Para isso, o piquete anterior (de onde os animais iriam sair) era observado e as amostras coletadas simulando o pastejo efetuado pelos animais. A forragem era coletada em, aproximadamente, 10 pontos aleatórios dentro de cada piquete, formando uma amostra composta.

As condições climáticas durante o período experimental constam na Tabela 3 .

O material colhido por meio do pastejo simulado foi analisado para as frações protéicas e composição da parede celular. As análises seguiram as metodologias de Goering \& Van Soest (1970) e Van Soest et al. (1991) para as determinações dos componentes da parede celular. Para determinação das frações nitrogenadas, adotaram-se as metodologias de Krishnamoorty et al. (1982) e Licitra et al. (1996). Para cada amostra, foram determinados: FDN, FDA, lignina, PB, nFDN, nFDA, Nsol, NnP e MM.

As frações FDN e FDA foram determinadas através do equipamento Ankon (Ankon 200 Fiber
Analyser da Ankon Technology Corporation), sendo adicionado o sulfito de sódio, com o objetivo de solubilizar a proteína aderida à parede celular (Mertens, 1998).

A lignina foi analisada com a adição de ácido sulfúrico $72 \%$ no resíduo insolúvel da determinação da FDA (Van Soest, 1982).

Para estimar a proteína total utilizou-se o equipamento da Leco FP 528 (Leco Corporation, St. Joseph, MI, EUA). As determinações das frações nitrogenadas (nFDN, nFDA, Nsol e NnP) foram realizadas em Macro Kjedal. A FDN e FDA utilizadas para a determinação do teor de nitrogênio foram analisadas em equipamento convencional de fibra, seguindo a metodologia de Goering \& Van Soest (1970), não se utilizando o sulfito de sódio.

Foram calculadas as frações dos carboidratos e da proteína seguindo-se a metodologia adotada para o programa de Cornell (CNCPS) (Sniffen et al., 1992). O NDT foi estimado pela equação de Weiss (1993).

A análise estatística foi realizada segundo um modelo de blocos completos ao acaso com medidas repetidas no tempo. As análises foram feitas usandose o programa Genstat 5.0 (GENSTAT, 1999).

Tabela 3 - Condições climáticas da área experimental ao longo do período de coleta de dados Table 3 - Meteorological variables during the experimental period

\begin{tabular}{|c|c|c|c|c|}
\hline $\begin{array}{l}\text { Ano/mês } \\
\text { Year/month }\end{array}$ & $\begin{array}{c}\text { Radiação global }\left(\mathrm{Cal} / \mathrm{cm}^{2} . \mathrm{d}\right) \\
\text { Global radiation }\end{array}$ & $\begin{array}{l}\text { Insolação }(\mathrm{h} / \mathrm{dia}) \\
\text { Insolation }\end{array}$ & $\begin{array}{l}\text { Temp. máxima }(\mathrm{C}) \\
\text { Maximum temp. }\end{array}$ & $\begin{array}{c}\text { Temp. mínima }\left({ }^{\circ} \mathrm{C}\right) \\
\text { Minimum temp. }\end{array}$ \\
\hline Out 1999 (Oct 1999) & 454 & 6,98 & 28,48 & 15,36 \\
\hline Nov 1999 (Nov 1999) & 478 & 7,04 & 29,47 & 15,70 \\
\hline Dez 1999 (Dec 1999) & 508 & 7,23 & 30,56 & 18,99 \\
\hline Jan 2000 (Jan 2000) & 464 & 6,37 & 30,22 & 19,09 \\
\hline Fev 2000 (Feb 2000) & 450 & 5,49 & 29,92 & 19,24 \\
\hline Mar 2000 (Mar 2000) & 411 & 5,42 & 29,68 & 18,53 \\
\hline Abr $2000(A p r 2000)$ & 451 & 9,08 & 29,36 & 14,48 \\
\hline Mai 2000 (May 2000) & 347 & 7,36 & 26,64 & 11,19 \\
\hline Jun 2000 (Jun 2000) & 304 & 6,68 & 27,16 & 11,36 \\
\hline Jul $2000($ Jul 2000) & 320 & 6,47 & 24,71 & 8,83 \\
\hline Ago 2000 (Aug 2000) & 324 & 5,74 & 26,53 & 12,50 \\
\hline Set $2000($ Sep 2000) & 396 & 6,17 & 27,20 & 15,10 \\
\hline Out 2000 (Oct 2000) & 480 & 7,20 & 32,07 & 17,99 \\
\hline Nov 2000 (Nov 2000) & 465 & 6,79 & 29,82 & 17,72 \\
\hline
\end{tabular}




\section{Resultados e Discussão}

Tanto para os componentes nitrogenados quanto para os carboidratos, não foi encontrada diferença $(\mathrm{P}>0,05)$ entre os tratamentos nos ciclos de pastejos avaliados.

Os maiores teores de FDN foram observados nos primeiros períodos (Tabela 4), que corresponderam às estações de primavera e verão, enquanto os menores foram para os meses de agosto e setembro (ciclos de pastejos 8 e 9 ).

Os valores de FDN, que variaram entre 62,79 e 68,33\%MS (Tabela 4), são semelhantes aos dados de literatura para o capim-Tanzânia (Rego et al., 2001). Rego et al. (2001) obtiveram valores de FDN entre 61,47 e $73,96 \%$ MS. Esses valores representavam diferentes extratos da planta em 4 alturas de pastejo. No entanto, ao se verificar os valores que seriam correspondentes às amostras de pastejo simulado (estratos superiores), os teores de FDN variaram entre 63,58 e 69,04\%MS.

Maiores teores de FDN foram também observados por Carnevalli et al. (1999) quando pastagens de Tifton-85 foram manejadas à maiores alturas. Na primavera, os teores de FDN foram mais elevados a 15 e $20 \mathrm{~cm}$ que a $5 \mathrm{~cm}$, enquanto no verão foi maior a $20 \mathrm{~cm}$ do que para as alturas de 10 e $15 \mathrm{~cm}$. Neste período, o teor de FDN foi menor a $5 \mathrm{~cm}$ do que para as outras alturas de pastejo.

Os teores de FDN não variaram $(\mathrm{P}>0,05)$ com a intensidade de pastejo. Isto pode estar associado à alta taxa de renovação de tecidos, proporcionada pela irrigação e pela elevada dosagem de nitrogênio (80 $\mathrm{kg} / \mathrm{ha}$ ) aplicada após cada pastejo.

A relação folha/haste foi menor $(\mathrm{P}>0,05)$ para $\mathrm{o}$ resíduo alto que para o resíduo baixo. No entanto, a variação ao longo do ano foi maior que entre os tratamentos. Em média, a porcentagem de folhas da planta toda foi de 56,$16 ; 50,62$; e 50,51\%, respectivamente para os resíduos baixo, médio e alto. Isto indica uma maior capacidade de seleção dos animais nos tratamentos de maior oferta de forragem (resíduo alto). A maior seletividade dos animais pela forragem pode ter suplantado uma eventual pior qualidade da planta nos resíduos médio e alto.

A amostra de pastejo simulado deve ser o mais próximo possível da dieta dos animais. Em pastagens manejadas com elevadas taxas de lotação, os erros na amostragem do pastejo simulado ficam minimizados, pois, apesar de existir seletividade, os animais fazem o pastejo por estratos horizontais, o que facilita a amostragem. Mesmo assim, o hábito de pastejo dos animais deve ser observado, pois a amostragem em extratos pode levar a erros na avaliação da qualidade da planta, caso a arquitetura da planta seja alterada durante a coleta (Molan et al., 1999).

A proporção de FDN de uma forragem é importante não só para a avaliação de sua composição química, mas também pelo fato de a FDN estar relacionada com consumo máximo de matéria seca (Mertens, 1994). Desse modo, plantas com teores maiores de FDN teriam menor potencial de consumo.

Os teores de FDA (Tabela 4) seguiram a mesma

Tabela 4 - Teor de FDN, FDA e lignina (\% da MS) de amostras de pastejo simulado de capim Tanzânia (Panicum maximum Jacq.). Médias de três níveis de resíduo pós-pastejo (baixo, médio e alto), ao longo de 10 ciclos de pastejos

Table 4 - NDF, ADF and lignin (\% DM) of Tanzânia grass simulated grazing samples collected along 10 grazing cycles, means of three post grazed stubbles (low, medium and high)

\begin{tabular}{lllllll}
\hline $\begin{array}{l}\text { Ciclos de pastejo } \\
\text { Grazing cycle }\end{array}$ & FDN & $\varepsilon^{1}$ FDN & FDA & $\varepsilon$ FDA & $\begin{array}{c}\text { Lignina } \\
\text { Lignin }\end{array}$ & $\begin{array}{c}\varepsilon^{1} \text { lignin } \\
\varepsilon \text { Lignin }\end{array}$ \\
\hline 1 & $N D F$ & $\varepsilon^{1} N D F$ & $A D F$ & $\varepsilon^{1} A D F$ & $3,10^{\mathrm{f}}$ & $\pm 0,12$ \\
2 & $68,33^{\mathrm{a}}$ & $\pm 0,61$ & $33,22^{\mathrm{abc}}$ & $\pm 0,46$ & $3,34^{\mathrm{ef}}$ & $\pm 0,12$ \\
3 & $66,15^{\mathrm{ab}}$ & $\pm 1,26$ & $33,18^{\mathrm{abc}}$ & $\pm 0,70$ & $3,80^{\mathrm{cde}}$ & $\pm 0,18$ \\
4 & $67,30^{\mathrm{a}}$ & $\pm 1,59$ & $34,89^{\mathrm{a}}$ & $\pm 0,67$ & $3,44^{\mathrm{de}}$ & $\pm 0,13$ \\
5 & $66,29^{\mathrm{ab}}$ & $\pm 0,63$ & $34,82^{\mathrm{ab}}$ & $\pm 0,35$ & $3,87^{\mathrm{bcde}}$ & $\pm 0,17$ \\
6 & $65,60^{\mathrm{ab}}$ & $\pm 1,26$ & $34,31^{\mathrm{ab}}$ & $\pm 0,62$ & $4,10^{\mathrm{abcd}}$ & $\pm 0,30$ \\
7 & $64,50^{\mathrm{ab}}$ & $\pm 1,01$ & $34,56^{\mathrm{ab}}$ & $\pm 0,60$ & $4,68^{\mathrm{a}}$ & $\pm 0,20$ \\
8 & $65,48^{\mathrm{ab}}$ & $\pm 1,69$ & $34,25^{\mathrm{ab}}$ & $\pm 0,94$ & $4,57^{\mathrm{ab}}$ & $\pm 0,25$ \\
9 & $63,26^{\mathrm{b}}$ & $\pm 1,36$ & $32,52^{\mathrm{b}}$ & $\pm 0,79$ & $4,22^{\mathrm{abc}}$ & $\pm 0,13$ \\
10 & $62,79^{\mathrm{b}}$ & $\pm 0,98$ & $32,65^{\mathrm{b}}$ & $\pm 0,57$ & $3,85^{\mathrm{bcde}}$ & $\pm 0,35$ \\
\hline
\end{tabular}

Médias seguidas da mesma letra na coluna não diferem significativamente pelo teste Tukey $(P>0,05)$.

Means followed by the same letter in the colunm do not differ by Tukey test $(P>.05)$.

${ }^{1} \varepsilon$ erro-padrão da média (standard error of mean). 
tendência que os de FDN, ambos apresentando menores concentrações no período de inverno $(\mathrm{P}<0,05)$ (ciclos de pastejos 8 e 9). Os teores de FDA variaram entre 32,55 e $34,89 \%$ da MS, o que é compatível com análises da parede celular de outras gramíneas e também do capim Tanzânia (Balsalobre, 1996; Rego et al., 2001). Teores de FDA superiores a $40 \% \mathrm{MS}$ podem ser encontrados em plantas com idade fisiológica avançada.

Os teores de lignina apresentaram tendências diferentes dos valores de FDA e FDN. Nos ciclos de pastejo iniciais ( 1 e 2) os teores foram menores do que nos ciclos 6, 7, 8 e 9 (Tabela 4). Os teores de lignina variaram entre 3,10 e 4,68 \% MS. Esse comportamento diferenciado dos componentes da parede celular pode promover variação em sua qualidade, pois as plantas com menores teores de FDN apresentaram os maiores teores de lignina. Isso é evidenciado quando se observa o comportamento da fração C (Figura 1). Essa fração corresponde a parte indisponível do total de carboidratos da planta (CT) (Sniffen et al., 1992).

A fração $\mathrm{C}$ foi menor para o ciclo de pastejo 1 $(14,14 \% \mathrm{CT})$ apesar de não ter diferença significativa dos teores encontrados para os ciclos de pastejo 2 , 4 e 5 . Os maiores valores para a fração $\mathrm{C}$ foram encontrados para os ciclos 7 e $8(22,80$ e $23,21 \% \mathrm{CT}$,

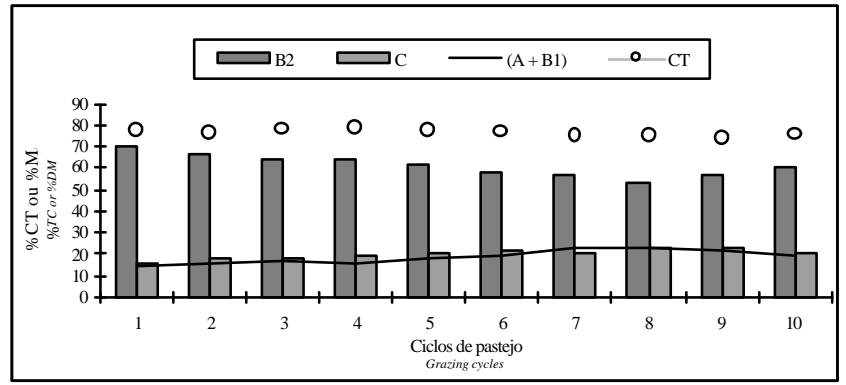

Figura 1 - Teor de carboidratos totais (\% MS) e fracionamento dos carboidratos (frações B2, $\mathrm{C}$ e $\mathrm{A}+\mathrm{B} 1$, expressas em \% dos carboidratos totais) de amostras de pastejo simulado de capim-Tanzânia (Panicum maximum Jacq.) para três níveis de resíduo pós-pastejo (baixo, médio e alto), ao longo de 10 ciclos de pastejo.

Figure 1 - Carbohydrate fraction (B2, $C$ and $A+B 1)$ expressed in total carbohydrates percentage and percentage of total carbohydrates in dry matter of Tanzaniagrass simulated grazing samples collected along 10 grazing cycles, means of three post grazed stubbles (low, medium and high). respectivamente), que também não foram diferentes significativamente em relação aos teores encontrados nos ciclos 6, 9 e 10. De modo geral, as amostras representativas dos meses de inverno apresentaram maiores teores de carboidratos indisponíveis quando comparadas às amostras de verão.

A pior qualidade da fração dos carboidratos, após o mês de maio (ciclo 6), pode ser explicada pelo florescimento das plantas. Ao longo do ano ocorreram vários períodos de florescimento. A maior porcentagem de perfilhos florescidos foi observada no mês de abril (ciclo de pastejo 5) (Santos, 2002), havendo um segundo pico de florescimento no mês de junho (ciclo de pastejo 7). Além disso, nessa época do ano (outono/inverno) é provável que tenha ocorrido redução da renovação de tecido e que a sobrevivência dos perfilhos tenha aumentado, o que explicaria uma maior lignificação e maior teor da fração $\mathrm{C}$ nos meses de julho/agosto.

$\mathrm{O}$ aumento no teor da fração $\mathrm{C}$ dos carboidratos foi acompanhado por redução da fração B2 (Figura 1). Para essa fração, os maiores teores foram observados nos ciclos de pastejo iniciais. O maior valor foi de 70,48 \%CT (ciclo 1) e o menor, de 53,61 \%CT (ciclo 8).

A porção dos carboidratos de rápida degradação ruminal (frações A e B1), que correspondem aos carboidratos solúveis e ao amido, compreenderam valores entre 15,38 e $23,18 \%$ CT, com média de $20,05 \%$ (Figura 1). A soma dos teores das frações A e B1 são maiores que os encontrados por Vieira et al. (2000), que em pastagens nativas, obtiveram teores de $\mathrm{A}+\mathrm{B} 1$ de 11,07 e 15,17 \%CT, respectivamente para o período da seca e das águas. Os valores encontrados por Vieira et al. (2000) para as frações de carboidratos de rápida degradação podem ter sido subestimadas, pois foram coletas da extrusa e, nesse caso, esses compostos podem se solubilizar na boca dos animais.

Em gramíneas tropicais, os CT representam a maior proporção da MS das plantas. Neste caso, os teores de CT variaram entre 74 e $78 \%$ MS. A variação na qualidade dessa fração interfere diretamente na disponibilidade de energia para o ruminante.

Os cálculos do NDT (Figura 2) mostram tendência de maiores valores nos ciclos em que a fração $\mathrm{C}$ dos carboidratos foi menor. Entretanto, esses ciclos foram os de maiores teores de FDN.

O NDT, calculado como porcentagem da matéria seca (Figura 2), variou entre 55,26 e 59,31\%. O 
menor valor foi para o ciclo de pastejo 7. Neste ciclo de pastejo foi observado o maior acúmulo de perfilhos florescidos (observação visual). Os maiores teores de NDT foram nos períodos de primavera e verão.

O teor de PB teve tendência de aumento ao longo dos ciclos de pastejos (Figura 2). Os menores valores (por volta de 11,5\%MS) foram obtidos nos primeiros 5 ciclos de pastejo, enquanto o maior valor foi para o último pastejo (14,61\%MS). O aumento do teor de proteína bruta ao longo dos ciclos de pastejo, provavelmente, foi devido ao manejo da adubação nitrogenada. Em virtude de se tentar isolar o fator irrigação na produção da forragem, a quantidade de nitrogênio aplicada em cada ciclo de pastejo ( $80 \mathrm{~kg} \mathrm{~N} / \mathrm{ha}$ ) foi a mesma.

Nos ciclos de pastejo de inverno a produção forrageira foi, aproximadamente, $50 \%$ da produção de verão (Penati, 2002). Portanto, é provável que a maior quantidade de nitrogênio no sistema tenha resultado em consumo de luxo desse nutriente e aumento do teor protéico.

O provável consumo de luxo pelas plantas durante os últimos ciclos de pastejo é evidenciado, também, pelo aumento nos teores de $\mathrm{NnP}$ e Nsol (Figura 3). O $\mathrm{NnP}$, corresponde à fração A para o programa de Cornell, enquanto a subtração do NnP do Nsol, nos indica o valor da fração B1, que teve variação entre

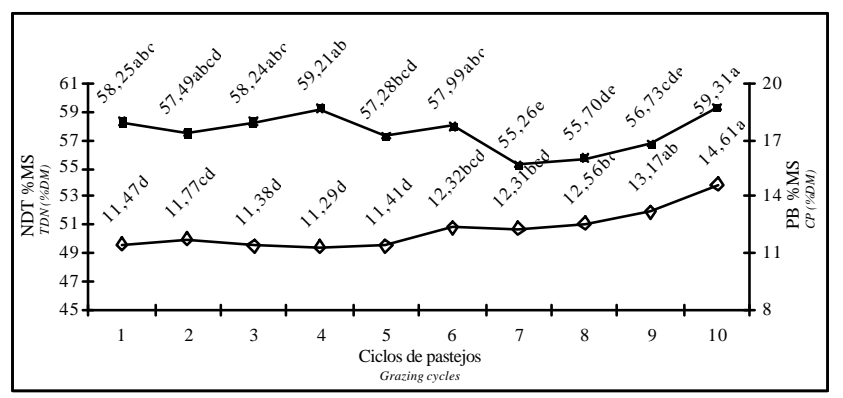

Figura 2 - Teor de NDT $(\square$ e proteína bruta $(\diamond)$ em $\%$ da matéria seca de amostras de pastejo simulado de capim-Tanzânia (Panicum maximum Jacq.), médias de três níveis de resíduo póspastejo (baixo, médio e alto) ao longo de 10 ciclos de pastejo. Médias seguidas da mesma letra não diferem significativamente pelo teste Tukey $(P>0,05)$.

Figure 2 - TDN $\square$ ) and $C P()$ (\%DM) of Tanzaniagrass simulated grazing samples collected along 10 grazing cycles, means of three post grazed stubbles (low, medium and high). Means followed by the same letter do not differ by Tukey test $(P>.05)$.
3,92 e 8,03\% da PB (Figura 5). A fração B1 tem pouca importância em gramíneas forrageiras, pois, normalmente, representa valores menores que $10 \%$ do total da proteína.

Os teores de NnP variaram entre 18,23 e $28,77 \%$ da $\mathrm{PB}$, sendo o menor valor para o primeiro ciclo de pastejo e os maiores para os últimos ciclos. $\mathrm{O}$ teor de Nsol variou de 24,97 a $35,97 \%$ PB. Portanto, o NnP representa em torno de 75 a $80 \%$ do Nsol.

A parte da proteína ligada à parede celular (nFDN e nFDA) que representa as frações B3 e C para Cornell, podem ser vistas na Figura 4. A fração nFDN foi a variável mais estável ao longo do ano, pois não apresentou nenhuma diferença $(\mathrm{P}>0,05)$ entre os ciclos de pastejo, representando em média, 49,11\% da $\mathrm{PB}$.

O nFDA apresentou maior variação $(\mathrm{P}<0,05)$. Os valores estiveram entre 6,48 e $11,94 \%$ da PB. Do mesmo modo que para a fração B 1 , pode-se dizer que o acúmulo de $\mathrm{N}$ na planta não se deu na forma de proteína aderida a parede, pois para os maiores valores de $\mathrm{PB}$ houve menores proporções de nFDA. Assim, as menores proporções de nFDA foram para os últimos ciclos de pastejos.

A fração B2, de degradação intermediária, apresentou variação entre 14,96 e 25,16 \% PB (Figura 5). Os maiores valores foram encontrados nos ciclos

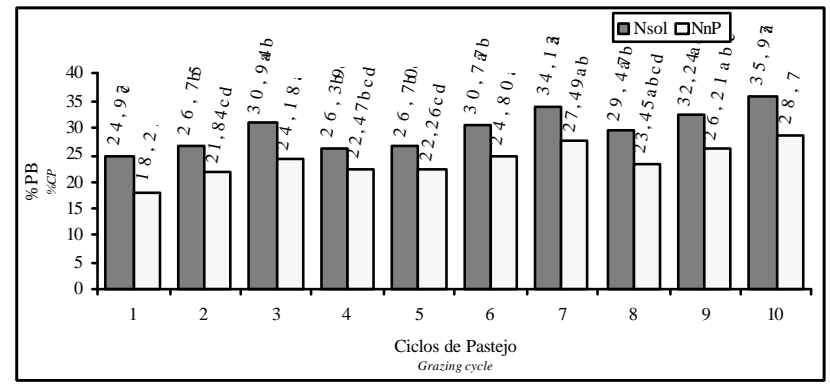

Figura 3 - Teor de $\mathrm{N}$ solúvel (Nsol) e de nitrogênio não protéico $(\mathrm{NnP})$ em \% do nitrogênio total de amostras de pastejo simulado de capim Tanzânia (Panicum maximum Jacq.), médias de três níveis de resíduo pós-pastejo (baixo, médio e alto), ao longo de 10 ciclos de pastejo. Médias seguidas da mesma letra não diferem significativamente pelo teste Tukey $(P>0,05)$.

Figure 3 - Soluble $N(N s o l \% C P)$ and non protein $N(N n P$ $\% C P$ ) of Tanzaniagrass simulated grazing samples collected along 10 grazing cycles, means of three post grazed stubbles (low, medium and high). Means followed by the same letter do not differ by Tukey test $(P>$.05). 


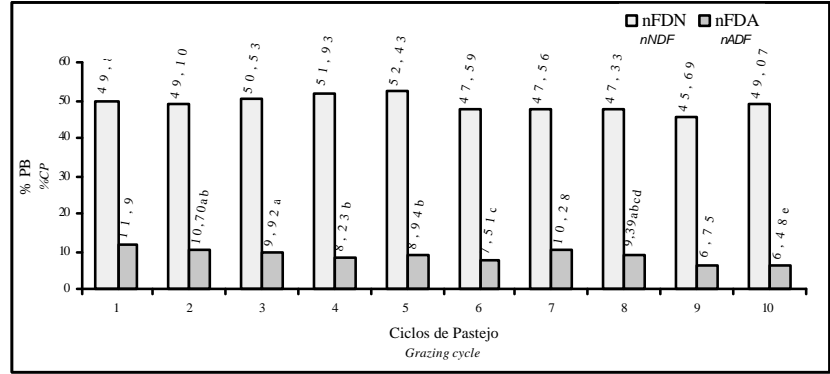

Figura 4 - Teor de nFDN e nFDA em \% do nitrogênio total de amostras de pastejo simulado de capimTanzânia (Panicum maximum Jacq.), médias de três níveis de resíduo pós-pastejo (baixo, médio e alto), ao longo de 10 ciclos de pastejo. Médias seguidas da mesma letra não diferem significativamente pelo teste Tukey $(P>0,05)$.

Figure 4 - nNDF and nADF (\%CP) of Tanzaniagrass simulated grazing samples collected along 10 grazing cycles, means of three post grazed stubbles (low, medium and high). Means followed by the same letter do not differ by Tukey test $(P>.05)$.

iniciais e o menor, no último ciclo de pastejo, mostrando que o acúmulo de $\mathrm{N}$ ocorrido na planta nos últimos ciclos não foi na forma de proteína verdadeira de degradação intermediária.

A fração B3 representa a proteína de maior proporção na planta. É obtida pela subtração do nFDN pelo nFDA e representa a proteína aderida à parede celular com potencial para ser degradada, no entanto, com baixa taxa de degradação. Em média, a fração B3 foi de $40 \%$ da PB (Figura 5).

Os teores de matéria mineral variaram entre 7,87 e 10,47 \% na MS. Esses valores elevados são comuns em pastagens tropicais adubadas.

Deve-se ter cuidado na avaliação do teor protéico de plantas tropicais, pois, em áreas bem manejadas e adubadas, esse poderá atingir teores elevados e, na maioria das vezes, maiores que a exigência de animais em crescimento e terminação (NRC, 1996). Isso poderá levar a conclusões equivocadas, sendo uma delas a de que existe proteína em excesso com relação à necessidade nutricional dos animais em plantas tropicais. No entanto, boa parte dessa proteína não é degradável (fração C). Outra porção é nitrogênio não protéico, que tem taxa de degradação extremamente alta, às vezes maior que $200 \% / \mathrm{h}$ (em não mais que 30 minutos se solubiliza).

A alta proporção de proteína solúvel (fração A), promoverá grandes perdas de nitrogênio via amônia;

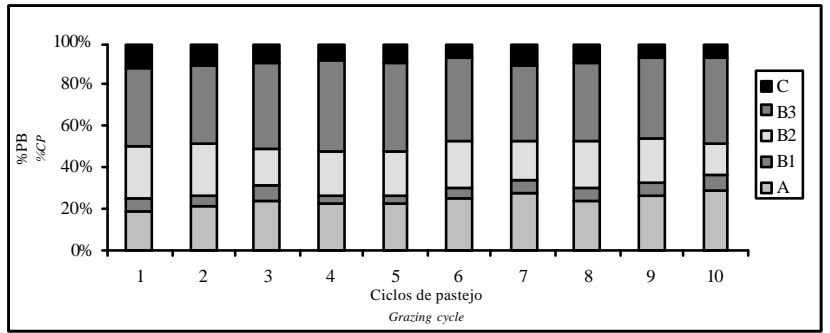

Figura 5 - Proporção das frações protéicas em \% da proteína de amostras de pastejo simulado de capim-Tanzânia (Panicum maximum Jacq.), médias de três níveis de resíduo pós-pastejo (baixo, médio e alto), ao longo de 10 ciclos de pastejo.

Figure 5 - Protein fractions ratio (\%CP) of Tanzaniagrass simulated grazing samples collected along 10 grazing cycles, means of three post grazed stubbles (low, medium and high).

essa pode ser reciclada para o rúmen, no entanto, uma parte deve ser metabolizada e retirada do organismo. Esse processo com gasto de energia é conhecido por custo uréia (Owens \& Zinn, 1988).

A uréia pode ser reciclada para o rúmen por duas vias: saliva ou parede ruminal. Essa última, graças à urease produzida por microorganismos, pois o tecido animal não produz urease. Quanto menor o teor de $\mathrm{PB}$ na dieta, maior a reciclagem de $\mathrm{N}$ na forma de uréia vinda do fígado para o rúmen. Owens \& Zinn (1988) citam que, em dietas contendo de 5 a $20 \%$ PB, a reciclagem foi, respectivamente, de 70 a $11 \%$ do nitrogênio consumido. De 23 a $92 \%$ da uréia pode ser reciclada para o rúmen.

$\mathrm{Na}$ avaliação do teor de proteína das plantas relacionado à exigência animal deve-se levar em consideração a categoria animal e a raça, pois, sabese que os zebuínos apresentam maior capacidade de reciclagem de uréia para o rúmen que os taurinos. Isso significa que os zebuínos podem apresentar desempenhos semelhantes em condições de menor disponibilidade de proteína degradável no rúmen, e que os taurinos respondem melhor à suplementação protéica que os próprios zebuínos.

A fração B3, como possui lenta taxa de degradação, dependendo da taxa de passagem da fase sólida pelo rúmen, apresentará baixa degradação (Balsalobre, 2002). Desse modo, as frações que representam 
cerca de $70 \%$ da proteína do capim Tanzânia (A, B3 e C) possuem problemas de utilização pelos ruminantes. Isso significa que, apesar dos altos teores de proteína nessas pastagens, poderá, em algum momento após o consumo da forragem pelos animais, haver déficit ruminal de proteína.

Por outro lado, o efeito negativo da lignina, observado pelos altos teores da fração $\mathrm{C}$ dos carboidratos, reduz significativamente a disponibilidade de energia das plantas tropicais para o ruminante. Entretanto, deve-se levar em consideração os bons teores da fração A + B1 dos carboidratos (em torno de $20 \%$ dos CT), que mesmo não tendo valores adequados em relação à fração A da proteína (apresentam taxas de degradação semelhantes), poderão levar a um bom aproveitamento de boa parte dessa fração protéica.

De forma geral, existem variações na qualidade da forragem ao longo do ano, tanto da parte protéica como dos carboidratos. No entanto, deve-se ressaltar que a qualidade da forragem em áreas irrigadas apresenta menores variações que em pastagens de sequeiro. Apesar disso, a pequena variação na qualidade nutricional das plantas, proporciona grandes alterações quando se avalia a relação da proteína degradável com a energia disponível no rúmen (Balsalobre , 2002). Desse modo, sistemas em pastagens de capim-Tanzânia irrigados, quando utilizarem suplementações concentradas, devem levar em consideração a qualidade nutricional das plantas, sendo que o tipo de concentrado deverá ser alterado de acordo com a qualidade da forragem ao longo do ano.

$\mathrm{O}$ fato de não haver diferenças significativas da qualidade da planta nos três tratamentos, indica que o desempenho animal poderá estar associado a algumas características físicas da planta que interfiram diretamente no consumo de matéria seca, somente isso poderia explicar ganhos de peso menores no tratamento de menor resíduo pós-pastejo, como determinado por Penati (2002).

\section{Conclusões}

O nível de resíduo pós-pastejo não influenciou as características qualitativas avaliadas

Menores teores de NDT e maiores proporções da fração C dos carboidratos, foram verificadas nos meses de julho a setembro.

Os teores de proteína podem ser considerados altos e tiveram tendência de aumento com o avanço dos ciclos de pastejos.
A maior proporção do $\mathrm{N}$ se encontra na parede celular, indicando que essa fração deve ser prioridade de estudos no tocante a cinética de degradação ruminal, para uma melhor caracterização da proteína das plantas de Tanzânia.

\section{Literatura Citada}

AGUIAR, S.V.H.; BALSALOBRE, M.A.A.; LABONIA, V.D. de et al. 2001. Proporção de partes morfológicas do capim Tanzânia (Panicum maximum Jacq.) em três intensidades de pastejo ao longo do ano. In: REUNIÃO ANUAL DA SOCIEDADE BRASILEIRA DE ZOOTECNIA, 38., 2001, Piracicaba. Anais... Piracicaba: Sociedade Brasileira de Zootecnia, 2001. p.342-343.

BALSALOBRE, M.A.A. Desempenho de vacas em lactação sob pastejo rotacionado de capim-elefante (Pennisetum purpureum Schum.). Piracicaba: Escola Superior de Agricultura "Luiz de Queiroz", 1996. 139p. Dissertação (Mestrado em Agronomia) - Escola Superior de Agricultura "Luiz de Queiroz", 1996.

BALSALOBRE, M.A.A. Valor alimentar do capim Tanzânia irrigado. Piracicaba: Escola Superior de Agricultura "Luiz de Queiroz", 2002. 113p. Tese (Doutorado em Agronomia) Escola Superior de Agricultura "Luiz de Queiroz", 2002.

BURLISON, A.J.; HODGSON, J.; ILLIUS, A.W. Sward canopy structure and the bite dimension and bite weight of grazing sheep. Grass and Forage Science, v.46, p.29-38, 1991.

CABAllero, R.; AlZUETA, C.; ORTIZ, L.T. et al. Carbohydrate and protein fractions of fresh and dried Common Vetch at three maturity stages. Agronomy Journal, v.93, p.1006-1013, 2001.

CARNEVALLI, R.A.; SILVA, S.C.; PEDREIRA, C.G.S. et al. Pasture and animal responses of Tifton- 85 swards grazed by sheep under continuous stocking. In: INTERNATIONAL "GRASSLAND ECOPHYSIOLOGY AND GRAZING ECOLOGY”, 1., 1999, Curitiba, PR.Proceedings...Curitiba: Universidade Federal do Paraná, 1999. p.357-361.

FOX, D.G.; SNIFFEN, C.J.; O'CONNOR, J.D. et al. A net carbohydrate and protein system for evaluating cattle diets: III. Cattle requirements and diet adequacy. Journal of Animal Science, v.70, p.3578 - 3596, 1992.

GENSTAT 5 Release 4.1 Reference Manual, Genstat 5 Committee ed. Numerical Algoritms Group, 1999.

GOERING, H.K.; Van SOEST, P.J. Forage fiber analyses (Apparatus, Reagents, Procedures, and Some Applications). Agricultural Handbook 379. ARS-USDA, Washington, D.C., 1970.

HALIM, R.A.; BUXTON, D.R.; HATTENDORF, M.J. et al. Water stress effects on alfalfa forage quality after adjustment for maturity differences. Agronomy Journal, v.81, p.189- 194, 1989.

HILLENSHEIM, A. Fatores que afetam o consumo e perdas de capim elefante (Pennisetum purpureum, Schum.) sob pastejo. Piracicaba: Escola Superior de Agricultura "Luiz de Queiroz", 1987.94p. Dissertação (Mestrado em Agronomia) - Escola Superior de Agricultura "Luiz de Queiroz", 1987.

KRISHNAMOORTHY, U.C.; MUSCATO, T.V.; SNIFFEN, C.J. et al. Nitrogen fractions in selected feedstuffs. Journal of Dairy Science, v.65, p.217, 1982.

LICITRA, G.; HERNANDEZ, T.M.; VAN SOEST, P.J. Standardization of procedures for nitrogen fractionation of rumi- 
nant feeds. Animal Feed Science Technology, v.57, p.347358, 1996

LIMA, G.F.C.; SOLLENBERGER, L.E.; MOORE, J.E. et al. Concentração e fracionamento do nitrogênio em gramíneas forrageiras tropicais e subtropicais. In: REUNIÃO ANUAL DA SOCIEDADE BRASILEIRA DE ZOOTECNIA, 36, 1999, Porto Alegre. Anais...São Paulo: Sociedade Brasileira de Zootecnia/Gmosis, [1999] 17 par. CD ROM. Forragicultura.

MALAFAIA, P.A.M.; VALADARES FILHO, S.C.; VIEIRA, R.A.M. et al. Determinação da cinética ruminal das frações protéicas de alguns alimentos para ruminantes. Revista Brasileira de Zootecnia, v.26, n.6, p.1243-1251, 1997.

MERTENS, D.R. Regulation of forage intake. In:FAHEY, G.C. Jr.; COLLINS, M.; MERTENS, D.R. et al. (Eds.) Forage quality, evaluation and utilization. Madison: 1994. p.450493.

MERTENS, D.R. NDF: fiber composition and value of forages with different NDF concentrations. In: SOUTHWEST NUTRITIONALECOLOGYMANAGEMENT CONFERENCE, 1988, Poenix. Proceedings... Poenix: Arizona State University, 1998. p.85-99.

MOLAN, L.K.; ROSSETO, F.A.A.; NUSSIO, L.G. et al. Avaliação do valor nutritivo em diferentes estratos de plantas de capim-elefante (Pennisetum purpureum Schum.) e capim Tanzânia (Panicum maximum Jacq.) sob pastejo. In:SIMPÓSIO DE INICIAÇÃO CIENTÍFICA DA USP, 1. 1999, Piracicaba. Anais...Piracicaba: FEALQ, 1999. p.378.

NATIONAL RESEARCH COUNCIL - NRC. Nutrient requirements of domestics animals. Nutrient requirements of beef cattle. Washington, D. C.: National Academy Science, 1996. 245p.

OWENS, F.N.; ZINN, R. Protein metabolism of ruminant animals. In: CHURCH, D.C. (Ed.) The ruminant animal, digestive physiology and nutrition. Englewood Cliffs: Prentice Hall, 1988. p.227-249.

PACIULLO, D.S.C.; MATTOS, J.L.S.; GOMIDE, J.A. et al. Proporção de tecidos espessura da parede celular em espécies de braquiária, cultivadas sob diferentes níveis de umidade do solo. In: REUNIÃO ANUAL DA SOCIEDADE BRASILEIRA DE ZOOTECNIA, 36, 1999, Porto Alegre. Anais... São Paulo:Sociedade Brasileira de Zootecnia/Gmosis, [1999] 17 par. CD ROM. Forragicultura.

PENATI, M. A. Estudo do desempenho animal e produção do capim Tanzânia (Panicum maximumJacq.) em um sistema rotacionado de pastejo sob irrigação em três níveis de resíduo pós pastejo. Piracicaba: Escola Superior de Agricultura "Luiz de Queiroz", 2002. 117p. Tese (Doutorado em Agronomia) - Escola Superior de Agricultura "Luiz de Queiroz", 2002.

REGO, F.C.A.; CECATO, U.; CANTO, M.W. et al. Qualidade do capim tanzânia (Panicum maximum Jacq. cv. Tanzânia-1) manejado em diferentes alturas, sob pastejo. In: REUNIÃO ANUAL DA SOCIEDADE BRASILEIRA DE ZOOTECNIA, 38., 2001, Piracicaba. Anais.... Piracicaba: Sociedade Brasileira de Zootecnia, 2001. p.117-118.
RUSSEL, J.B.; O'CONNOR, J.D.; FOX, D.G. et al. A net carbohydrate and protein system for evaluating cattle diets: I. Ruminal fermentation. Journal of Animal Science, v.70, p.3551-3561, 1992.

SANTOS, P.M. Estudo de algumas características agronômicas dePanicum maximum(Jacq.) cvs. Tanzânia e Mombaça para estabelecer seu manejo. Piracicaba: Escola Superior de Agricultura "Luiz de Queiroz", 1997. 62p. Dissertação (Mestrado em Agronomia) - Escola Superior de Agricultura "Luiz de Queiroz", 1997.

SANTOS, P.M.; BALSALOBRE, M.A.A.; CORSI, M. Efeito da frequiência de pastejo e da época do ano sobre a produção e a qualidade emPanicum maximum cvs. Tanzânia e Mombaça. Revista Brasileira de Zootecnia, v.28, p.244-249, 1999.

SANTOS, P.M.; BALSALOBRE, M.A.A.; CORSI, M. Participação de gerações de perfilhos na produção do capim Tanzânia. In: REUNIÃO ANUAL DA SOCIEDADE BRASILEIRA DE ZOOTECNIA, 38., 2001, Piracicaba. Anais... Piracicaba: Sociedade Brasileira de Zootecnia, 2001. p.123-124.

SANTOS, P.M. Controle do desenvolvimento das hastes do capim Tanzânia: um desafio. Piracicaba: Escola Superior de Agricultura "Luiz de Queiroz", 2002. 98p. Tese (Doutorado em Agronomia) - Escola Superior de Agricultura "Luiz de Queiroz", 2002.

SNNIFEN, C.J.; O'CONNOR, J.D.; Van SOEST, P.J. et al. A net carbohydrate and protein system for evaluating cattle diets: II. Carbohydrate and protein availability. Journal of Animal Science, v.70, p.3562-3577, 1992.

Van SOEST, P.J. Nutritional ecology of the ruminant. Oregon: Ed. Corvallis, E.E.U.U.O., \& B. Books, 1982. p. 374.

Van SOEST, P.J.; ROBERTSON, J.B.; LEWIS, B.A. Methods for dietary fiber, neutral detergent fiber and nostarch polysaccharides in relation to animal nutrition. Journal of Dairy Science, v.74, p.3583-3597, 1991.

VIEIRA, R.A.M.; PEREIRA, J.C.; MALAFAIA, P.A.M. Fracionamento dos carboidratos e cinética de degradação in vitro da fibra em detergente neutro da extrusa de bovinos a pasto. Revista Brasileira de Zootecnia, v.29, n.3, p.889-897, 2000.

WEISS, W.P. Predicting energy values of feeds. Journal of Dairy Science, v.76, p.1802-11, 1993.

WILSON, J.R.; MERTENS, D.R. Cell wall accessibility and cell structure limitations to microbial digestion of forage. Crop Science, v.35, n.1, p.251-259, 1995.
Recebido em: 30/01/02

Aceito em: 22/11/02 